ORIGINAL ARTICLE

\title{
Outcome of Two Treatment Regimens in the Management of Intracranial Fungal Granuloma
}

\author{
SHAHID MEHMOOD, HAFIZ JAWAD ALI, AMIR AZIZ \\ Mohammad Anwar Chaudary, Tariq Salah-ud-Din \\ Department of Neurosurgery, Lahore General Hospital, Lahore
}

\begin{abstract}
Objective: Two treatment regimens means either you have to completely/near total excise the granuloma with sinus clearances (extra-dural) OR don't touch it, even minimal invasive procedure such as burr hole biopsy can be fatal (intra-dural).

Introduction: The diagnosis of intracranial fungal granuloma almost always remained a challenge for neurosurgeons because of their rarity, alter behavior and lack of diagnostic tools. These infections are now easily diagnosed because of increased awareness and understanding regarding this pathology, better diagnostic tools and an increase in immunocompromised/immunocompetent hosts (from any cause). Most often, the fungal granulomas are due to contiguous spread of the infection from the paranasal sinuses and ear. Rarely, they may be due to hematogenous spread from a focus in the lungs. The infection can spread from sinuses to invade the brain parenchyma. Once it involves the brain parenchyma then the course of the disease is fulminant. Contrast enhanced C.T. and MRI of brain are investigations of choice. Although morbidity and mortality from central nervous system (CNS) mycosis has improved over years; mortality often reaches $75-100 \%$ despite an intensive treatment strategy (surgery followed by antifungal medications). Fungal hyphae are better demonstrated on periodic acid Schiff and Gomorimethanamine silver stain. This study will help us to describe an improved management approach to such patients with intracranial fungal granuloma depending upon the extent of spread, whether extradural or intradural. If the granuloma is extradural, the better management is extensive surgical approach with sinuses clearance followed by antifungals remains the gold standard. If the granuloma is intradural, then surgery is abandoned/ avoided to the extent possible.
\end{abstract}

Study Design: Case series.

Setting of Study: Department of Neurosurgery, Lahore General Hospital, Lahore.

Duration: One year from June 2012 to July 2013.

Materials and Methods: Twenty patients of intracranial fungal granuloma were included in this study.

Results: The mean \pm SD age was $33.76 \pm 5.43$ years. Out of total 20 patients, most of the patients 10 (50\%) were in age group between 20 - 30 years, $6(30 \%)$ were between 31 - 40 year, and $3(15 \%)$ patients were between $41-$ 50 years. Only $1(5 \%)$ patient was in age group of $51-60$ year. There were $12(60 \%)$ male and $8(40 \%)$ were female patients. Thus the male to female ratio was 1.5:1. Out of total 20 cases, there were 18 (90\%) patients had Aspergillosis type and only 2 (10\%) patients had Mucormycosis type of fungal infection.

Conclusions:

- According to the two treatment regimens, whenever the granuloma is intradural/ intraparenchymal surgery is avoided/abandoned but when the granuloma is extradural a more aggressive surgical approach is planned.

- In our study most of the patients were within the age range 20 - 30 years of age with a mean age of 33.76 years with male to female ratio of 1.5:1. 
- $\quad$ There were $90 \%$ of patients of aspergillosis and only $10 \%$ patients of mucormycosis.

Abbreviations: MRI: Magnetic Resonance Imaging. CT: Computed Tomography. CNS) Central Nervous System.

Key Words: Intracranial fungal granuloma, aspergillosis, mucormycosis, immunocompromised, immunocompetent, intradural, extradural.

\section{INTRODUCTION}

Intracranial fungal infections are seen most of the time among immunocompromised/immunocompetent hosts, of any type such as increased age, cancer chemotherapy, malignancies, excessive corticosteroids use, intravenous drug abusers and trauma/surgery, organ transplant, diabetes mellitus \& HIV infections etc. Increased awareness among clinicians, better imaging techniques \& histopathology staining has made these infections to diagnose as early as possible. ${ }^{1-7}$

In the brain these infections most commonly affect the corticomedullary junctions owing to increased vascularity, spread from the nearby structures such as the paranasal sinuses and ears. Hematogenous spread to the brain from a focus in the lungs is very rare. Isolated intracranial fungal granulomas without sinuses involvement or a focus anywhere else are extremely rare. ${ }^{1,2,8}$

Intracranial fungal infections can present as headache, allergic or chronic sinusitis, nasal blockage, vomiting, Nausea, proptosis/ptosis, detoriation of vision, seizures, drowsiness, cranial nerves involvement and papilloedema. Contrast enhanced C.T. and MRI of brain (Fig. $1 \& 2$ ) are investigations of choice but neither of these provide definite diagnosis, they only detect intracranial mass or masses and involvement of paranasal sinuses..$^{1,2,8,9}$

Intracranial fungal granuloma once diagnosed can be treated conservatively and surgically. Surgical management is planned depending upon the site involved (extradural/intradural) with concomitant use of antifungal medications. Despite such an intensive treatment strategy the mortality and morbidity is extremely high and mortality often reaches $100 \%$, whenever the granuloma is intradural and treated surgically. ${ }^{1,3-7}$

Fungal hyphae are poorly visible on routine hematoxylin eosin stain and are better demonstrated on periodic acid Schiff and Gomorimethanamine silver stain. Aspergillus spores are most commonly found in areas where the climate is hot and dry with agricultural dust such as Pakistan, India, Saudi Arabia, Africa and California in United States. ${ }^{1}$

This study will help us to describe an improved management approach to such patients with intracra- nial fungal granuloma depending upon the extent of spread, whether extradural or intradural. If the granuloma is extradural, the better management is extensive surgical approach with sinuses clearance followed by antifungals remains the gold standard. If the granuloma is intradural, then surgery is abandoned/ avoided and only antifungal drugs are used.

\section{OBJECTIVES}

To describe the outcome of management of intracranial (extradural/intradural) fungal granuloma.

\section{OPERATIONAL DEFINITIONS}

\section{Transethmoidal/Trans-nasal Approach}

It was used to take biopsy and maximum debulking of the granuloma from Ethmoidal/sphenoidal air cells spreading to the skull base or adjacent areas.

\section{Burr Hole Biopsy}

There was suspicion of diagnosis/ when nasal sinuses were not involved.

\section{Craniotomy}

Used for excision of fungal granuloma from brain parenchyma (poor outcome). Combined approaches like fronto-orbital craniotomy, modified bifrontal craniotomy and simple craniotomy operation.

There was involvement of maxillary sinuses, orbital area, optic nerve and anterior or middle skull base areas.

\section{MATERIAL AND METHODS}

\section{Study Design}

It was a case series study.

\section{Study Universe}

This study was conducted at the Department of Neurosurgery, Lahore General Hospital Lahore. 


\section{Study Population}

20 patients of intracranial fungal granuloma were included in the study from June 2012 to July 2013.

\section{Inclusion Criteria}

- Gender: Both male and female.

- Age: 20-60 years.

- All cases of intracranial fungal granuloma whether biopsy defined or else (high probability of fungal granuloma).

\section{Exclusion Criteria}

- Patients refusing from surgery.

- Patients not fit for major surgery (Anesthesia unfit).

- All other granulomas including Tuberculoma/ brain abscess.

- Patients with renal (raised creatinin $>1$ ) or hepatic (Billirubin > 2) dysfunction.

\section{RESULTS}

This study was carried out in the Department of Neurosurgery, Lahore General Hospital, Lahore. The study included 20 cases of intracranial fungal granuloma. These patients were admitted during the period of June 2012 to July 2013.

Twenty patients of intracranial fungal granuloma were included, shown in Table 1 . Out of total 20, most of the patients $10(50 \%)$ were in age group between 20 - 30 years, $6(30 \%)$ were between $31-40$ year, and $3(15 \%)$ patients were between $41-50$ years. Only 1 (5\%) patient was in age group between $51-60$ years. The mean age was $33.76 \pm 5.43$ year.

Table 1: Age Distribution of Patients $(n=20)$.

\begin{tabular}{|c|c|c|}
\hline Age years & No. of Patients & Percentage \\
\hline $20-30$ & 10 & 50.0 \\
\hline $31-40$ & 6 & 30.0 \\
\hline $41-50$ & 3 & 15.0 \\
\hline $51-60$ & 1 & 5.0 \\
\hline
\end{tabular}

There were $12(60 \%)$ male and $8(40 \%)$ were female patients. Thus the male to female ratio was 1.5:1 (Figure 3).
Mean $\pm \mathrm{SD}=33.76 \pm 5.43$

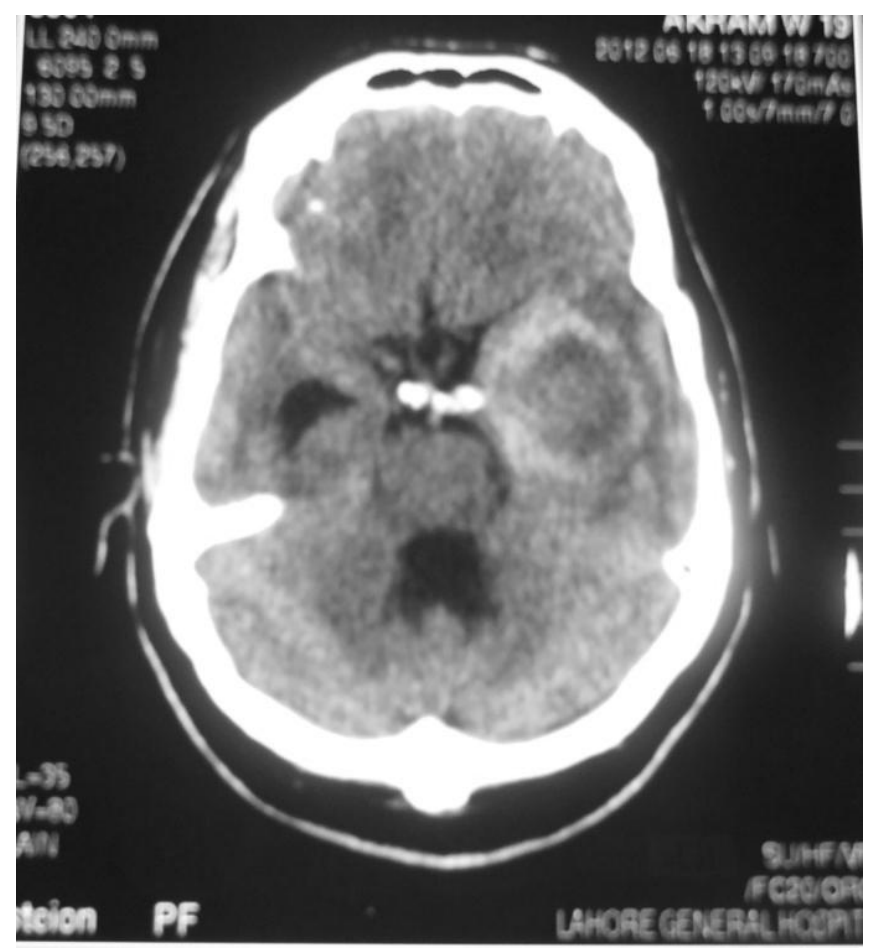

Fig. 1: Computed tomography scan of a patient with aspergillosis showing hyperdense lesion in the left temporal lobe.

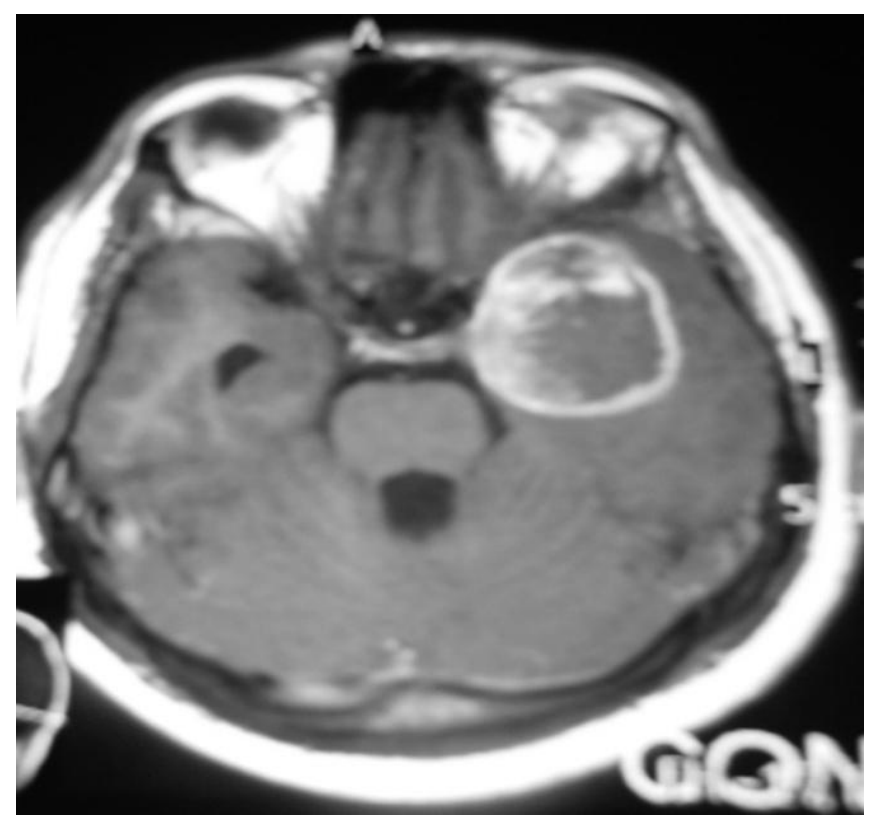

Fig. 2: Magnetic resonance imaging with gadolinium of a patient with aspergillosis showing heterogeneous ring enhancing lesion in left temporal lobe. 


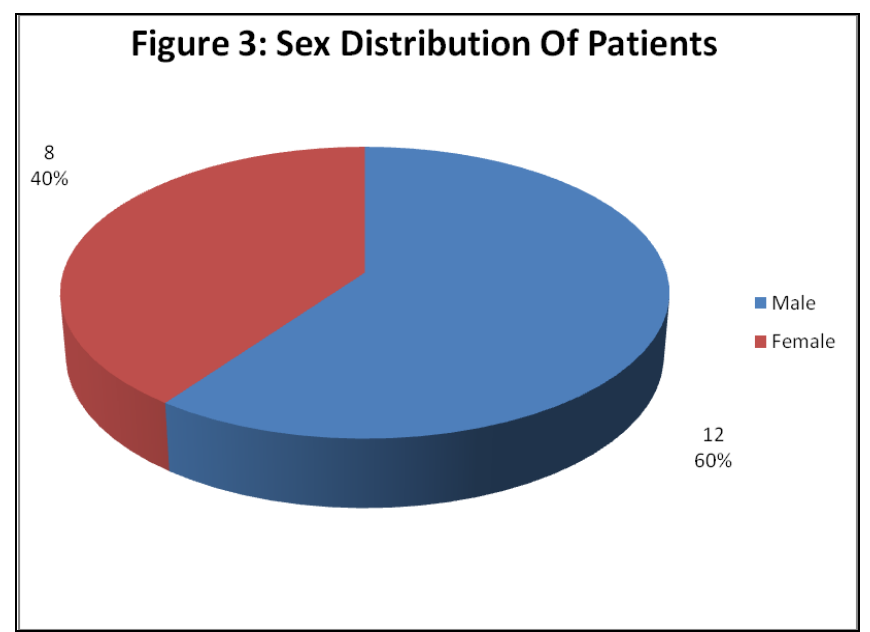

Fig. 3: Sex Distribution of Patients $(n=20)$.

Out of total 20 cases, there were $18(90 \%)$ patients had Aspergillosis type and only $2(10 \%)$ patients had Mucormycosis type (Figure 4).

Out of 20 patients, 9 (45\%) patients had intradural/ intraparenchymal fungal granuloma, while $11(55 \%)$

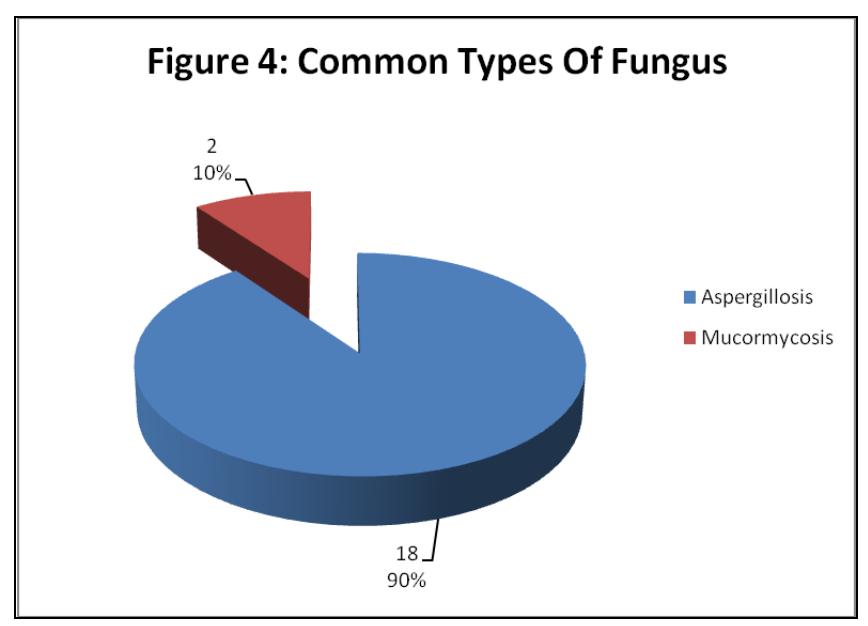

Fig. 4: Male to female ratio $=1.5: 1$.

Table 2: Location, Survival \& Mortality.

\begin{tabular}{|l|c|c|c|}
\hline Location & $\begin{array}{c}\text { No. of } \\
\text { Patients } \\
\text { (Percentage) }\end{array}$ & Survival & Mortality \\
\hline $\begin{array}{l}\text { Intradural/ } \\
\text { intraparenchymal }\end{array}$ & $9(45 \%)$ & $\begin{array}{c}3 \\
(33.33 \%)\end{array}$ & $\begin{array}{c}6 \\
(66.67 \%)\end{array}$ \\
\hline Extradural & $11(55 \%)$ & $\begin{array}{c}9 \\
(81.82 \%)\end{array}$ & $\begin{array}{c}2 \\
(18.18 \%)\end{array}$ \\
\hline
\end{tabular}

had extradural fungal granuloma (Table 2).

Table 2 Shows that out of the $9(45 \%)$ patients of intradural/intraparenchymal fungal granuloma, 6 $(66.67 \%)$ patients expired (these patients underwent either minimal invasive surgery such as burr hole biopsy or craniotomy), 3 (33.33\%) patients survived (these patients were diagnosed on the basis of radiology and were treated conservatively), thus the mortality ratio was $66.67 \%$ in case of intradural fungal granuloma. $11(55 \%)$ patients had extradural fungal granuloma. Out of these 11 patients $2(18.18 \%)$ patients expired (possibly because of underlined concomitant disease) while $9(81.82 \%)$ patients survived, thus the mortality ratio was $18.18 \%$ (Table 2 ).

Table 3: Diagnosis Criteria $(n=20)$.

\begin{tabular}{|l|c|c|}
\hline & $\begin{array}{c}\text { No. of } \\
\text { Patients }\end{array}$ & Percentage \\
\hline Sinuses clearance & 10 & 50.0 \\
\hline Burr hole biopsy & 5 & 25.0 \\
\hline Radiologic impression & 3 & 15.0 \\
\hline Craniotomy & 2 & 10.0 \\
\hline
\end{tabular}

Patients who survived showed great response to inj. Amphotericin B and cap. Sporonox. The response was noted in terms of improvement of symptoms. Radi-ologically these patients showed replacement of granuloma with dead or necrotic tissue after six months of treatment.

\section{DISCUSSION}

Twenty patients were included in this study. The study was carried out in the Department of Neurosurgery at Lahore General Hospital, Lahore.

Fungal infection of the central nervous system (CNS) is a life-threatening disease. ${ }^{10}$ Spread of the infection to the brain is usually via blood stream, rarely there is no primary source found. After lungs and paranasal sinuses the third most common site of fungal infection is the brain. When the CNS is involved the course of the disease is usually fulminant mainly because that CNS is a sanctuary site and drug penetration is often inadequate. ${ }^{11-13}$

In our study $50 \%$ of patients were between $20-30$ years of age. $6(30 \%)$ patients were between $31-40$ years and $3(15 \%)$ patients were between $41-50$ years 
while only $1(5 \%)$ patient was $51-60$ years of age. The mean \pm SD age was $33.76 \pm 5.43$. The mean age varies, according to the inclusion criteria of various studies. A study done by Ramesha the mean age was 41.2 years and age range from $23-66$ years. ${ }^{7}$ A study carried out by Lin the mean age was 44.2 years with a range of $3-91$ years. ${ }^{14}$ Another study conducted by Reed the mean age was 51 years. ${ }^{15,16}$ A study done by Nithyanandam the mean age was 48.2 years with age range from $14-69$ years. ${ }^{17}$ In another study reported by Selvam (Indian) the mean age was 33.2 years which is comparable with our study with a slight difference. $^{6}$

In the present study out of total 20 patients there were 12 patients $(60 \%)$ male while 8 patients $(40 \%)$ were female with male to female ratio of $1.5: 1$. In a study carried out by Lin distribution of gender there were $162(72 \%)$ were male while 63 (28\%) patients were female. ${ }^{14}$ In another study done by Nithyanandam there were 18 patients male and 16 patients were females with a male to female ratio 1.19:1 which is comparable with our study with a slight difference. ${ }^{17}$

In our study the mortality ranged from $66-100 \%$ in cases whenever the granuloma was intradural/ intraparenchymal after any surgical intervention. However, the mortality rate was less than $20 \%$ in cases when the granuloma was extradural with or without sinus involvement, in such cases the mortality was always associated with underlined co morbid conditions. Such statistics are slightly comparable with many studies. In a study carried out by Siddiqui et al, whenever the granuloma is extradural aggressive surgical management is planned followed by antifungal therapy but when the granuloma is intradural/ intraparenchymal surgery is avoided to the extent possible in such cases stereotactic burr hole biopsy is done only to confirm the diagnosis. $^{11}$

In the present study there were $18(90 \%)$ patients had aspergillosis type of infection while only $2(10 \%)$ patients had mucormycosis which is slightly different from Challa study, such a difference is due to geographic occurrence of fungus type. ${ }^{1}$ In comparison with a study carried out by Challa, out of total 86 patients there were $13(15.1 \%)$ patients had intracranial fungal granulomas. Out of them, there were $8(61.5 \%)$ patients with Aspergillus spp. granulomas. ${ }^{9}$

In our study 9 (45\%) patients had intradural/ Intraparenchymal fungal granuloma while $11(55 \%)$ had extradural fungal granuloma. Out of the 9 patients of intradural fungal granuloma $5(25 \%)$ of the patients had burr hole biopsy, 1 (5\%) patient had craniotomy and $3(15 \%)$ patients were diagnosed based on radiology. All the $6(30 \%)$ patients of intradural fungal granuloma underwent either minimal invasive surgery or craniotomy expired within a week of the procedure. However the $3(15 \%)$ patients of intradural fungal granuloma diagnosed based on radiology, clinical evidence and involvement of sinuses survived. These patients had intradural lesion which was iso to hypointense on $\mathrm{T}_{2} \mathrm{~W}$ images with contrast enhancement and sinuses involvement. These patients were initially treated with steroids and other measures to reduce the intracranial pressure, but their condition detoriate so steroids were stopped and antifungal therapy started that had lead to the clinical improvement. The role of steroids is controversial in many studies.

In our study $11(55 \%)$ patients had extradural fungal granuloma with involvement of the sinuses. Out of these 11 patients, $8(40 \%)$ patients had sinus clearance surgery either transnasally or externally transethmoidally, while one patient (5\%) had craniotomy and excision of extradural aspergilloma in left temporal region, one patient of extradural fungal granuloma expired possibly because of underlined co-morbid disease. All the patients were treated with antifungal drugs after any surgical procedure/ diagnosis. These patients were closely monitored for their Symptomatology both clinically and radiologically. Their symptoms improved within days of treatment. Radiologically the affected area showed dead/ necrotic tissue after six months in maximum cases.

\section{CONCLUSION}

It is concluded that all over the world fungal infections of the central nervous system are increasingly being recognized. It is generally seen in immunocompromised patients but some fungi are known to affect the apparently immunocompetent host. Now an increased awareness among physicians and a high level of suspicion help in establishing the diagnosis.

- According to the two treatment regimens, whenever the granuloma is intradural/ intraparenchymal surgery is avoided/abandoned but when the granuloma is extradural a more aggressive surgical approach is planned.

- In our study most of the patients were within the age range $20-30$ years of age with a mean of 33.76 years while male to female ratio was 1.5:1.

- There were $90 \%$ of patients of aspergillosis and only $10 \%$ patients of mucormycosis.

- When there is a lesion that is hypo to isointense on 
$\mathrm{T}_{2} \mathrm{~W}$ MRI with contrast enhancement and there is involvement of sinuses always suspect for fungus.

- When there is involvement of sinuses, optic apparatus, duration of symptoms is short ( $<6$ months) and the clinical condition of the patient detoriates with steroids then there is probability of fungus.

\section{RECOMMENDATIONS}

Whenever the granuloma is intradural/intraparenchymal surgery is abandoned treat with antifungal drugs.

\section{Address for correspondence: Dr. Shahid Mehmood Department of Neurosurgery Consultant Neurosurgeon Peshawar, KPK Contact: 0333-9206010 Email:pakbird78@yahoo.com}

\section{REFRENCES}

1. Anwar, M., Fauzia, S., Khalid, M., Zafar, I., Naveed, A., Tariq, S. Intracranial fungal granuloma various treatment modalities depending upon the anatomical structures involved. Pak J Neurol Surg. 2009; 13 (1): 1-11.

2. Asif, M., Shahid, M., Tanweer, A. MRI features of intracranial fungal granuloma taking histopathology as the gold standard. Pak J Neurol Surg. 2015; 19 (3): 166172.

3. Eileen, PS., Lindsey, R., Baden, Joel, TK. Fungal brain infections. Current Opinion in Neurol. 2008; 21: 34752.

4. Murthy, J.M. Fungal infections of the central nervous system: the clinical syndromes. Neurol India, 2007; 55: 221-25.

5. Murthy, J.M., Sundaram, C., Prasad, V.S., Purohit, A.K., Rammurti, S. Laxmi V. Aspergillosis of central nervous system: A study of 21 patients seen in an university hospital in south India. J Assoc Physicians India, 2000; 48: 677-81.

6. Selvam M, Pande A, Chakravarthy VM, Ramamurti R.
Invasive rhino-cerebral fungal granuloma: Neurol India, 2010; 58 (2): 270-76.

7. Ramesha, K.N., Kate, M.P., Kesavadas, C., Radhakrishnan, V.V., Nair, S., Thomas, S.V. Fungal infections of the central nervous system in HIV-negative patients: Experience from a tertiary referral center of South India. Ann Indian Acad Neurol. 2010; 13: 112-6.

8. Azarpira, N., Esfandiari, M., Bagheri, HM., Rakei, S., Salari, S. Cerebral aspergillosis presenting as a mass lesion. Brazilian J Infect Dise. 2008; 12 (4): 349-51.

9. Challa, S., Uppin, GS., Purohit, KA. Isolated cerebral Aspergillus granuloma with no obvious source of infection. Neurology India, 2007; 55 (3): PP. 289-91.

10. Chakrabarti, A., Sharma, A., Sood, A., Grover, R., Sakhuja, V., Prabhakar, S. Changing scenario of cryptococcosis in a tertiary care hospital in north India. Indian J Med Res. 2000; 112: 56-60.

11. Siddiqui AA, Shah AA, Bashir SH. Craniocerebral aspergillosis of sinonasal origin in immunocompetent patients: Clinical spectrum and outcome in 25 cases. Neurosurg. 2004; 55: 602-11.

12. Pagano, L., Offidani, M., Fianchi, L., Nosari, A., Candoni, A., Piccardi, M. Mucormycosis in hematologic patients. Haematologica. 2004; 89: 207-14.

13. Pagano, L., Girmenia, C., Mele, L. Infections caused by filamentous fungi in patients with hematologic malignancies. A report of 391 cases by GIMEMA Infection Program. Haematologica. 2001; 86: 862-70.

14. Lin, J.S., Schranz, J., Teutsch, M.S. Aspergillosis case fatality rate: Systematic review of the literature. Clin Infect Dis. 2000; 32 (3): 358-66.

15. Reed, C., Bryant, R., Ibrahim, A.S., Edwards, J., Filler, S.G., Goldberg, R., Spellberg, B. Combination polyenecaspofungin treatment of rhino-orbital-cerebral mucormycosis. Clin Infect Dis. 2008; 47: 364-71.

16. Reed, C., Ibrahim, A., Edwards, J.E., Walot, I., Spellberg, B. Deferasirox, an iron-chelating agent, as salvage therapy for rhinocerebral mucormycosis. Antimicrob Agents Chemother. 2006; 50: 3968-9.

17. Nithyanandam, S., Jacob, M.S., Battu, R.R., Thomas, R.K., Correa, M.A., D'Souza, O. Rhino-Orbito-Cerebral Mucormycosis: A retrospective analysis of clinical features and treatment outcomes. Indian $\mathrm{J}$ Ophthalmol. 2003; 51: 231-6. 
AUTHORS DATA

\begin{tabular}{|c|c|c|c|c|}
\hline Name & Post & Institution & E-mail & Role of Authors \\
\hline Dr. Shahid Mehmood & $\begin{array}{l}\text { Consultant } \\
\text { Neurosurgeon }\end{array}$ & $\begin{array}{c}\text { Department of } \\
\text { Neurosurgery, KPK, } \\
\text { Peshawar }\end{array}$ & pakbird78@yahoo.com & Paper Writing \\
\hline Dr. Hafiz Jawad Ali & PGR & \multirow{4}{*}{$\begin{array}{c}\text { Department of } \\
\text { Neurosurgery, PGMI / } \\
\text { AMC and Lahore General } \\
\text { Hospital, Lahore }\end{array}$} & & Data Collection \\
\hline Dr. Amir Aziz & Associate Professor & & & Tables \\
\hline $\begin{array}{l}\text { Dr. Mohammad Anwar } \\
\text { Chaudary }\end{array}$ & Professor & & & Corrections \\
\hline Dr. Tariq Salah-ud-Din & $\begin{array}{l}\text { Professor of } \\
\text { Neurosurgery }\end{array}$ & & & Supervision \\
\hline
\end{tabular}

Date of Submission: 15-12-2017

Date of Printing: 15-12-2017

Peer Reviewed by Dr. Babar Butt, Khurrum Ishaque and Chief Editor Prof. Dr. Muhammad Anwar Chaudary and others. 